\section{LA SACRALIZACIÓN DE LA PERSONA: SOCIOHERMENÉUTICA DE LOS VALORES}

\author{
Celso Sánchez Capdequí \\ Departamento de Sociología, Universidad Pública de Navarra \\ celso.sanchez@unavarra.es
}

Cómo citar este artículo/ Citation: Sánchez Capdequí, C. (2013). "La sacralización de la persona: sociohermenéutica de los valores". Arbor, 189 (761): a042. doi: http://dx.doi.org/10.3989/ arbor.2013.761n3010

Recibido: 15 abril 2011. Aceptado: 25 octubre 2012

RESUMEN: Este trabajo analiza los cambios sociales de la religión en nuestras sociedades. Aunque los sociólogos clásicos anunciaron su desaparición, la religión perdura en la sociedad actual pero con un rostro secular. Uno de sus símbolos es la persona. Emile Durkheim habló de la "sacralización de la persona" como una nueva expresión de lo sagrado. Recientemente Hans Joas aborda el problema de los valores y dialoga con Durkheim para explicar las nuevas formas de lo sagrado. La persona sería el valor universal que incluye a todos los hombres independientemente de su cultura, género, creencias religiosas, etc. Los Derechos Humanos son la institución que representa la nueva divinidad secular de la persona.

PALABRAS CLAVE: Religión; sacralización de la persona; secularización; valores; ritual; Derechos humanos.

\section{INTRODUCCIÓN}

Ha sido una constante en el proyecto científico de la modernidad la alta valoración otorgada al horizonte de los hechos empíricos como fuente de conocimiento incuestionable. Las lógicas y las regularidades que explican el curso de las cosas y, en especial, el orden natural que las gobierna, solo pueden desentrañarse

\section{THE CONSECRATION OF THE PERSON: SOCIO- HERMENEUTICS OF VALUES}

Copyright: (c) 2013 CSIC. Este es un artículo de acceso abierto distribuido bajo los términos de la licencia Creative Commons Attribution-Non Commercial (by-nc) Spain 3.0.

ABSTRACT: This paper analyses the social changes religion has undergone in our societies. Although the classical sociologists announced its disappearance, religion remains present in contemporary society but with a secular face. One of their symbols is the person. Emile Durkheim spoke of the "sacralisation of the person" as a new expression of the sacred. Recently Hans Joas addressed the issue of values and discussed the explanation of the new forms of the sacred with Durkheim. The person would be the universal value that includes all humankind regardless of culture, gender, religious beliefs, etc. Human Rights are the institution that represents the new secular divinity of the person.

KEYWORDS: Religion; sacralisation of the person; secularization; values; ritual; Human Rights.

atendiendo con detalle al discurrir de la experiencia aparentemente caótico e imprevisible. Los determinismos rectores de la vida natural que proclamó la ciencia natural con el advenimiento de la modernidad fueron incorporados al horizonte de la filosofía y las ciencias sociales decimonónicas. Bajo el primado de la metáfora de la biología, el objeto propiamente cultural (o social), al igual que el natural, opera desde un 
mecanismo inexorable que dirige sus procesos y que elimina cualquier tipo de accidente y contingencia en los mismos.

La cuestión hermenéutica del significado de los hechos naturales y los actos humanos se ignora porque el guión, el único guión que relata el curso de los acontecimientos, el de la evolución y la diferenciación funcional, se impone sin dejar espacio a la intervención humana en el entorno que habita. El componente contingente de la acción y la voluntad humanas queda anulado en un modelo de comportamiento que, en la ciencia natural y social, se reafirma en el afán de control y anticipación del futuro. Hasta ese momento, al decir de Michel Foucault, "el mundo está cubierto de signos que es necesario descifrar" $(1989,40)$. A partir de ahora, el mundo de la experiencia pierde su espesor simbólico y el anuncio profético de desencantamiento del mundo que Max Weber predijo para Occidente se abre paso como el hecho incontrovertible que define el impulso racionalizador y secularizador de la modernidad.

En este contexto cultural definido por la hegemonía incuestionable de los hechos empíricos uno de los datos incontrovertidos es la paulatina desaparición de la religión de los marcos de convivencia social. En los albores del pensamiento sociológico (A. Comte, H. Spencer, K. Marx, G. Simmel) se anuncian sus últimos días toda vez que la iniciativa humana se hace cargo de la gestión y organización del diseño social. Las contribuciones de la razón científica constituyen un instrumento de alcance desconocido para penetrar y, así, controlar los misterios más recónditos de la cosas. El hombre moderno sueña con habitar un mundo transparente en el que nada escapa a su ilimitada capacidad de conocimiento. Lo sagrado, como núcleo de la experiencia religiosa y límite (hasta entonces) de la razón humana, se constriñe en el escenario moderno secularizado y deja el territorio expedito para la orientación racional y estratégica de los individuos. El horizonte de experiencia se pliega a la voluntad de conocimiento y el control científico luego de haber despojado de interrogantes de ultimidad y de trascendencia la experiencia humana.

Sin embargo, la misma tozudez de los hechos, que un siglo antes ofrecía una convivencia transida de racionalización, hoy revela la resistencia de la experiencia religiosa a abandonar los actuales modelos sociales. Ha vuelto o, en realidad, nunca ha dejado de estar. Si acaso, ha buscado nuevas espacios para expresarse. Lo sagrado habita la experiencia contemporánea a pesar de su pálpito secular. El dominio ultraterre- no ya no constituye su referencia. En la experiencia circundante el hombre de nuestro tiempo encuentra señales, signos y símbolos que invitan a la lectura e interpretación de surcos de trascendencia en medio de un entorno secularizado. Instalada en la dimensión intramundana, la religión se incorpora a la vida individual como foco de experiencias de ultimidad. La huella de lo divino se hace carne en instituciones, organizaciones y valores transidos de un valor absoluto.

El trabajo hermenéutico se reivindica como tarea indagatoria que interroga a los hechos sociales para ahondar en sus pautas de sentido. Instituciones de nuestro tiempo como el Tribunal Internacional de la Haya, la ONU y, en especial, los Derechos Humanos, expresan un discurso simbólico cargado de resonancias semánticas evocadoras de un nuevo foco de sacralización, la persona. Aunque fue Emile Durkheim el que anticipó esta nueva disposición del núcleo sagrado de nuestra sociedad que se expresa en lo secular, como un simbolismo laico (como el jurídico-legal) y en un tono que favorece la inclusión de la pluralidad inherente a la extensa familia humana, es el sociólogo alemán Hans Joas el que, desde un horizonte de pensamiento integrador de los enfoques hermenéutico y neopragmatista, hace suya aquella herencia durkheimiana para entrar en el debate sobre los valores, sus procesos de formación y su articulación social en los modelos sociales actuales cargados de contingencia.

A la base de esta indagación teórica se encuentra el supuesto hermenéutico de que en la convivencia social rige una objetividad al igual que en los procesos naturales, pero con la diferencia de que su origen es social, "resultado de la intersubjetividad" (Alonso, $1998,28)$ y sustentada en una interpretación simbólica que galvaniza y selecciona eso llamado "mundo" y "realidad". En esa interpretación se expresa la dimensión creativa de una sociedad que, en sintonía con el pensamiento nietzscheano, ha infundido valor al desnudo y anónimo horizonte de los hechos empíricos. Ese valor es la persona. En ella se siente reconocida la inmensa mayoría de los individuos contemporáneos. Una vez más, al decir de Miguel Beltrán, "la realidad social exige ser interpretada, hecha inteligible gracias a la indagación de su sentido, un sentido 'socialmente puesto'"' $(2003,21)$.

\section{NUEVOS EPISODIOS DE LO SAGRADO: LA PERSONA}

Una de las voces más autorizadas en el pensamiento sociológico, Emile Durkheim, defendía en Las formas elementales de la vida religiosa que lo sagrado no desaparecería en el transcurso del trance moderno 
porque constituye el elemento desencadenante de las tramas de valor de la vida intersubjetiva. El texto se publica en 1912, en pleno descrédito del hecho religioso acosado por una atmósfera hostil y adversa ante cualquiera de sus expresiones sociales. Durkheim advierte que las sociedades no pueden sobrevivir ni cohesionarse sin formas de veneración que convoquen a sus integrantes en una narrativa común. Necesitan formas simbólicas con las que proyectarse como un horizonte compartido elevado. En sus propias palabras, "una sociedad no puede crear ni recrear sin crear, a la vez, el ideal. Esta creación no constituye para ella una especie de acto subrogatorio por medio del cual, una vez ya formada, se completaría: constituye el acto por el que se hace y se rehace periódicamente" (1992, 393).

Esta afirmación cobra especial relevancia para las sociedades modernas debido a su diseño institucional basado en el modelo de la diferenciación funcional y la especialización técnica. Más que nunca, las sociedades contemporáneas necesitan una argamasa simbólica que reúna en un valor compartido la complejidad funcional y la multiplicación identitaria que las caracterizan. Se trata del soporte semántico en el que, a pesar de la fragmentación reinante, se reconocen y se identifican los miembros de la sociedad, más allá de sus biografías personales, orígenes culturales y actividades profesionales. En él perdura el surco de un Nosotros que aglutina al conjunto de los habitantes del planeta en torno a un destino común, a modo de una moral laica y en calidad de un sistema de valor cultural integrador de la variedad del fenómeno humano. Su proceso formativo responde a la fuerza instituyente de lo sagrado que retorna periódicamente ofreciendo cauce expresivo a los nuevos sistemas de creencias.

Durkheim añade que nuestros modelos de convivencia, como el resto de las sociedades precedentes, integra en su articulación interna la fibra moral de la creencia pero orientándola hacia el horizonte intramundano. Así las cosas, ideales como la Patria, el Progreso, la Razón científica, la Persona, condensan la capacidad idealizadora que encierra la presencia de lo sagrado. Las nuevas esperanzas sociales se sitúan entre las cosas pertenecientes a la experiencia empírica y relucen y brillan con especial intensidad porque en ellas, de una u otra forma, se encuentra el poder humano capaz de gestionar su propia biografía y el curso de la historia sin apoyo metafísico ultraterreno. La religión ha dejado de sacralizar el más-allá del dominio intramundano, pero no por ello se ha esterilizado su capacidad de idealización y condensación simbólica. Tan solo se ha desplazado su orientación. Se encarna en instancias y realidades que se confunden con lo más próximo y cercano. En ellas palpitan intensamente las creencias contemporáneas y se proyectan las esperanzas de la sociedad en un mundo venidero colmado de plenitud.

En la experiencia de lo sagrado tiene lugar la proyección de valor sobre un entorno empírico al que carga de sentido. Se trata de la interpretación hermenéutica de la vida social que confiere unidad moral y cognitiva al conjunto heteróclito de la experiencia circundante. De este modo, hechos brutos se convierten acontecimientos significativos y trascendentes: al sacralizarse devienen valor. Más que un problema reducido a creer o no creer, la experiencia de lo sagrado retorna desatando los valores con los que los actores cubren de sentido los cursos rutinarios y previsibles de su tiempo. En ellos se juegan sus relaciones de autoidentificación simbólica, los proyectos de una vida significativa y la redefinición de la situación (global) en la que viven.

A juicio de Durkheim, lo sagrado se expresa en una proyección común. Su mayor contribución al devenir de la vida colectiva consiste en aglutinar en un ideal compartido al conjunto diverso y complejo de la sociedad moderna. Alza a los actores por encima de los afanes utilitaristas de cada miembro ofreciéndoles un horizonte cargado de sentido que abre la puerta a la cooperación y al entendimiento e infunde valor y orientación a sus proyectos vitales. Se constituye en pauta de valor porque representa al conjunto que se encarna en cada uno de ellos, porque goza de una autoridad de la que nadie duda, porque genera adhesión afectiva entre las biografías individuales. En palabras del propio Durkheim, "la sociedad ideal no está por fuera de la sociedad real, sino que forma parte de esta" (Ibid., 394).

A lo largo del trabajo "Individualismo y los intelectuales" (1973), Durkheim indaga en los cimientos hermenéuticos que encarnan los valores rectores de las sociedades contemporáneas. En el individuo se concentran las características que definen la religión para Durkheim en tanto "cuerpo de creencias y prácticas colectivas revestidas de una cierta autoridad" (Ibid., 51). Según sus propias palabras, "esta persona humana (personne humaine), cuya definición es la piedra toque que distingue el bien del mal, se considera como sagrado en el sentido ritual de la palabra. Comparte la majestuosidad trascendente que las iglesias de toda época confieren a sus dioses; se concibe como un 
ser investido de ese atributo misterioso que crea un vacío ante las cosas sagradas, que las aparta de los intercambio ordinarios y las aísla de la circulación cotidiana. $Y$ el respeto que inspira procede precisamente de esa fuente. Cualquiera que intente degradar la vida humana, la libertad humana, el honor humano, nos inspira un sentimiento de horror semejante al que siente el creyente de cualquier credo al asistir a la profanación de su ídolo. Se trata de una ética que no consiste simplemente en una disciplina higiénica o en una economía prudente de la existencia; es una religión en la que, al mismo tiempo, el hombre es el fiel y el dios" (Ibid., 46).

En el individuo se dan cita las tramas sagradas de la nueva religión contemporánea. Remite a una realidad situada entre los materiales de la experiencia cotidiana que, por la veneración que despierta en la sociedad, adquiere la condición de acontecimiento extraordinario. Habita las tramas de la vida cotidiana pero las trasciende porque en ella la sociedad palpa la majestad de lo sagrado. Ahora, "la humanidad se colma de respeto y es sacralizada" (Ibid., 48). Se trata del elemento que promueve y explica que los actores "participen del mismo horizonte y compartan una misma fe" (Ibid., 48). Esta idea de individuo "no supone una glorificación del yo sino del individuo en general. No surge del egoísmo sino de la simpatía por todos los humanos, de una piedad inmensa ante el sufrimiento, de todas las miserias del hombre, de una imperiosa necesidad de combatirlas y mitigarlas, de un irrenunciable anhelo de justicia" (Ibid., 48-9).

En la sacralización de la persona prende, según Durkheim (Ibid., 53), el legado de la religión cristiana. Por un lado, esta devoción enseña que el valor moral de los hechos debe analizarse a partir de la intención de la voluntad íntima del individuo que se considera agente soberano de su propia conducta, responsable de sus actos ante sí mismo y ante Dios. Además, con la separación definitiva entre los dominios de lo espiritual y lo terrenal, el mundo queda en manos del hombre y se abre paso la actividad del científico y el intercambio de conocimientos. Esto explica el paulatino e imparable progreso del espíritu científico en el entorno cultural occidental marcado por la impronta de la religión cristiana.

\section{LO SAGRADO Y LA FORMACIÓN DE LOS VALORES}

Los análisis de Durkheim parten de una circunstancia muy concreta en la que las viejas imágenes trascendentes del mundo se han debilitado fruto de una diferenciación funcional que obliga a los actores a adaptarse a otros ritmos de vida urbanos muy diferentes de los propiamente naturales y a convivir con actores de orígenes culturales muy diversos. Las rígidas estructuras normativas de las sociedades tradicionales se diluyen dando lugar a modelos en los que los individuos se hacen cargo de las narrativas hermenéuticas de sus vidas en contacto con los nuevos entornos cambiantes en que viven. Con sus propios términos, la solidaridad mecánica ha dado paso a la solidaridad orgánica al tiempo que la complejidad de la circunstancia contemporánea sirve como espejo para revelar lo mucho compartido por la variedad reinante en el existir humano. Esta mutación en la dimensión estructural y organizativa de la modernidad se corresponde con un cambio moral de enorme alcance para Durkheim, el de la irrupción del derecho restitutivo que sustituye al derecho represivo de las sociedades tradicionales. De esta manera, una justicia difusa y sin instituciones especializadas en la que la sociedad venga una falta lesiva para la cohesión social deja espacio a otro modelo de derecho con órganos institucionales claramente diferenciados en los que priman las medidas reparadoras sin carácter expiatorio. Se trata de un proceso social y jurídico contrario a cualquier forma de despotismo en el que "el individualismo se ha desarrollado en valor absoluto, penetrando en regiones que originariamente le estaban cerradas" $(1987,235)$.

En el transcurso de la vida moderna se impone el convencimiento moral de que el valor y el ideal de la humanidad expresa un nuevo lugar de encuentro y entendimiento en el que tienen cabida todos los humanos por el simple hecho de serlo: y de serlo sin adjetivos (culturales, políticos, de género, etc.). Se adivina en la persona un valor que viene a compensar y suturar las muchas y continuas brechas técnicas, económicas y culturales que surgen en un contexto global marcado por la irrefrenable tendencia a la diferenciación (de funciones técnicas, clases económicas y culturas). Destaca por su alto componente inclusivo e integrador ya que ningún individuo queda fuera de su alcance. Se reivindica a modo de una moral laica y descentrada basada en el consenso universal de que "necesitamos interpretar el mundo no desde una perspectiva de aquellos con los que ya tenemos establecidos los nexos afectivos, sino desde una perspectiva 'de mayor humildad entre nuestros hermanos y hermanas'” (Joas, 2008, 174). No se remite a un individuo o grupo concreto, sino "al hombre mismo" (Durkheim, 1973, 52). Y esto se debe a que "cada conciencia individual contiene algo divino y se encuentra revestido de una cualidad que la convierte en sagrado e inviolable ante los otros" (Ibid., 1973, 52). Precisa- 
mente eso que comparte cada uno de los individuos que pueblan el planeta es la dignidad de la persona. En este sentido, "la noción de dignidad constituye un valor en sí. Dicho de otro modo, los llamados valores fundamentales -libertad, justicia e igualdad- no pueden menoscabarse ni restringirse. Como valor incondicionado su validez no descansa en ninguna condición" (Bohr, 2008, 185).

Este cambio cultural forma parte de una metamorfosis de mayor calado en la que, como advierte Charles Taylor, tiene lugar "la afirmación de la vida corriente" $(1996,230)$. Con el protagonismo de la Reforma protestante, se impone la idea de que las obligaciones religiosas en su sentido más pleno son realizadas mejor por laicos en la "profesión" que por el clero en las comunidades monásticas aisladas. Propiamente esto no supone el declive del clero sino el ensalzamiento de lo laico. Esta idea coincide más con el diagnóstico de Durkheim que con el de Weber: se estaría más cerca de una sacralización del mundo que de un inexorable desencantamiento de la historia (Joas, 2007, 152).

El valor de la dignidad de la persona no debe ser entendido como habitualmente se ha hecho en fases históricas precedentes cargadas de resonancias religiosas, es decir, fuera del alcance del entendimiento humano y alejado de la experiencia inmediata. Muy al contrario, el valor de la dignidad se expresa con absoluta claridad y constituye la piedra angular de buena parte de las instituciones políticas representativas de nuestro tiempo que se han hecho eco en sus estructuras normativas y jurídicas del carácter sagrado de la persona. Desde esta perspectiva, "las reformas de la ley penal y la práctica penal, así como la creación de los derechos humanos a finales del siglo XVIII, son una expresión de un profundo giro cultural, a través del cual la persona humana en sí misma se convierte en un objeto sagrado" (Joas, 2008, 169).

Así las cosas, esta indagación teórica sobre la fibra hermenéutica de las actuales sociedades es más consciente que nunca de la contingencia inherente a toda propuesta de valor en el contexto de una sociedad diferenciada y articulada sobre un pluralismo que exige argumentación y justificación en las decisiones sociales. Bajo el enfoque de la génesis de los valores, Hans Joas elabora una pauta de reflexión que, lejos de abordar el asunto de los valores desde una preexistencia metafísica o una mera funcionalidad socializadora, incide en su formación histórica cargada de contingencia y sometida, por tanto, a un permanente debate intelectual y político acerca de la posibilidad de integrar bajo una normativa común y universal las muchas y diversas sensibilidades sociales que se reconocen en el valor de la persona.

La propuesta teórica de Hans Joas incide en que los valores nacen como experiencia de autotrascendencia (Selbstraszendenz) en la que los actores se autorrepresentan en el símbolo que comunica y une sus biografías dentro de un relato que perdura más allá de las contingencias históricas del vivir y convivir humano. En sintonía con las aportaciones de Durkheim, surgen de procesos históricos transidos de una emoción compartida, de una adhesión afectiva generadoras de una visión común y aglutinante. Lejos de derivar de principios morales abstractos y metafísicos, los valores son deudores de momentos de extraordinaria intensidad emocional en los que los actores se sienten invadidos por una fuerza anónima que incita a la comunión de cuerpos y mentes reafirmando el ideal común como un poder que les cruza y les trasciende. Liberados del control racional, los individuos suman y funden sus emociones bajo la crecida de la fuerza moral del valor social vigente en ellos.

Sin embargo, sobre la base de estos procesos de adhesión prerracional, los valores se hacen visibles en cuerpos normativos en los que se justifican ante el resto de la sociedad en la búsqueda del reconocimiento universal. En la sociedad contemporánea las formas de creencia han de homologarse con el universalismo ético imperante en ellas. Esto solo es posible buscando el consenso del conjunto de la sociedad y, por tanto, reinventando creativamente, y a la luz de determinados problemas concretos, una estructura normativa general que incluya e integre las muchas expresiones de la condición humana. Este proceso consistente en la generalización de valores, en expresión de Talcott Parsons, pone en evidencia que los valores incluyen en su seno una tensión inexorable entre lo bueno y lo justo, entre ideales, que no son fruto de una elección racional sino de identificaciones afectivas, y estructuras normativas, que deben expresar e incluir las muchas y diversas sensibilidades sociales que las forman y las conforman. Según Joas, "de acuerdo con esto, nuestra vida se desarrolla siempre en la tensión entre estos dos polos y lo único que podemos hacer es buscar una síntesis armónica entre ellos" $(2002,37)$.

El valor de la sacralización de la persona no agota el tejido axiológico de nuestras sociedades, pero sí es el único que pretende armonizar y articular un lenguaje común en el que las derivas endógenas y excluyentes de cualquier otro pueden mitigarse. Compite con, y en ocasiones, padece, la aplicación radical de 
otros valores seculares que forman parte de la agenda moderna, como son la patria, la razón científica, la cultura, la etnia, etc. Es más, su visibilidad queda en entredicho por la radicalidad identitaria que, en ocasiones y según casos concretos, impera en la adhesión incondicional a estos símbolos. Sin embargo, sus rasgos constitutivos, ya señalados por Durkheim, como la secularización, el universalismo ético y la racionalización justificativa, imprimen un sello muy singular a sus planteamientos. No en vano, se trata de un valor que pretende convocar a todos los miembros de la condición humana en torno a un horizonte compartido a partir de lo que les une y no les separa: el carácter absoluto de todo ser humano.

\section{LOS DERECHOS HUMANOS: LA INSTITUCIÓN DE LA SACRALIZACIÓN DE LA PERSONA}

Uno de los espacios en los que se expresa la sacralización de la persona es el de los Derechos Humanos entendido como escenario normativo en el que se hace cuerpo lo mucho compartido por la variedad reinante en la condición humana. El tejido jurídico de las sociedades contemporáneas incorpora esa mutación cultural de los últimos siglos y asume el propósito de velar por su defensa y promoción universal. Se trata de un logro moral de la civilización que tiende a englobar al conjunto de la humanidad, que no contempla ningún límite de tipo político, religioso, cultural, étnico y que responde al fondo secular y universalista que activa su despliegue. En palabras de Joas, "la creencia en la dignidad humana y en los derechos humanos nos afecta a todos - y a todos en igual grado. Sacraliza al joven y al anciano, al inteligente y al discapacitado mental" $(2003,268)$.

Sin embargo, la paulatina incorporación histórica no se da en el marco de un proceso lineal e irreversible, ni en todos los entornos con procesos sociales semejantes ni con tiempos de desarrollo similares. Estados soberanos en los que aún persiste la pena de muerte, el castigo físico de los reos, la desigualdad de derechos entre hombres y mujeres, la ausencia de libertad de expresión, asociación, prensa, etc., constituyen resistencias que impiden su institucionalización social. Por otra parte, aunque los Derechos Humanos encuentran su inspiración original en episodios filosóficos de la cultura occidental (Kant, Rousseau, etc.), en la sociedad global deben afrontar aún retos pendientes como, por ejemplo, una reformulación intercultural de sus contenidos, una coordinación sistemática de distintas disposiciones jurídicas y una redefinición de las relaciones entre Derechos Humanos, autodeterminación nacional y soberanía estatal (König, 2002, 47).

\section{CONCLUSIÓN}

Son muchas las voces que se inclinan a pensar que la situación moral del presente cabe definirla a partir de conceptos como "liberalización" o "pérdida de valores". Sin embargo, se dan otras opciones, entre ellas, la que defiende este trabajo y que señala a la sacralización de la persona como fuente de valor universal e integrador. Este valor nos une más allá de nuestras diferencias. Se ha constituido en la interpretación simbólica donde se reconocen todos los humanos por el simple hecho de serlo.

\section{BIBLIOGRAFÍA}

Alonso, Luis Enrique (1998). La mirada cualitativa en sociología. Madrid: Fundamentos.

Beltrán, Miguel (2003). La realidad social. Madrid: Tecnos.

Bohr, Christoph, (2008). "Wert und Würde". En Andreas Rödder y Wolfgang Elz (eds.), Alte Werte-Neue Werte. Gottingen: Vandenhoeck\&Ruprecht.

Durkheim, Emile (1973). “Individualism and the intellectuals". En Robert Bellah (ed.), Emile Durkheim on Morality and Society. Chicago: The University of Chicago Press.

Durkheim, Emile (1987). La división del trabajo social. Madrid: Akal.
Durkheim, Emile (1992). Las formas elementales de la vida religiosa. Madrid: Akal.

Foucault, Michael (1989). Las palabras y las cosas. México: Siglo XXI.

Joas, Hans (1997). Die Entstehung der Werte. Francfort del Meno: Suhrkamp.

Joas, Hans (2002). Creatividad, acción y valores. México: Universidad Autónoma Metropolitana.

Joas, Hans (2003). "Max Weber und die Entstheung der Menschenrechte. Eine Studie über kulturelle Innovation". En Albert, G.; Bienfait, A.; Sigmund, S. and Wendt, C. (eds.), Ds Weber-Paradigma. Tübingen: Mohr Siebeck.
Joas, Hans (2007). “Die Logik der Gabe und das Postulat der Menschenwürde". En Michael Gabel y Hans Joas (eds.), Von der Ursprünglichkeit der gabe. Friburgo: Karl Alber.

Joas, Hans (2008). "Punishment and Respect. The Sacralization of the Person and Its Endangerment". Journal of Classical Sociology, Vol.8 (2), p.159-177.

König, Matthias (2002). Menschenrechte bei Durkheim und Weber. Francfort del Meno: Campus Verlag.

Taylor, Charles (1996). Las fuentes del yo. Barcelona: Paidós. 